\title{
Editorials
}

\section{Quality of life for people with learning disability throughout the life span}

\author{
ANN Gath, Professor of Developmental Psychiatry, University College, \\ London WC1E 6AU
}

\section{The ethics of primary prevention and the value of human life}

It is accepted that primary prevention of the major impairments which lead to severe learning disability involves looking at problems arising at conception or even before. Only a minority of cases can be attributed to major gene effects. Those due to dominant genes rely on a high mutation rate as sufferers are unlikely to have children but most situations involve apparently normal people who carry recessive genes or are at high risk of producing a child with a chromosomal anomaly. When a couple are known to have a high risk of having a child with a severe disability, such as a one in four chance of San Fillippo disease, one of the group of inborn errors of metabolism, the muco-polysacchroidoses, in which the child is initially normal at birth, but gradually changes in appearance, with intellectual deterioration, exceptionally severe behaviour disorder, and neurological changes leading to death in the teens, there can be few who are unable to appreciate that the quality of life for that family is best served by pre-natal diagnosis followed by termination.

However, most cases are less clear-cut. Modern screening techniques give their results in terms of betting odds, much longer than usually perceived as an outside chance at Newmarket or even Aintree. How do couples make decisions on the basis of 1 in 100 of a condition about which they know little? In the case of Down's syndrome, a risk of that order is usually thought to justify amniocentesis, with at least an equal chance of losing a healthy foetus. However, the amniocentesis may reveal another condition, such as Turner's syndrome, which will lead to a child who can be induced to menstruate but will never bear a child of her own, will have only minor cognitive problems with predominantly spatial defects and when growing up will be much more likely to be an ideal little daughter with a tidy bedroom than most teenage girls. Just as difficult a decision can arise with Fragile $\mathrm{X}$, where a severely affected male is a possible outcome, but a girl may grow up to have an ordinary life, though her family may well comment that she was "none too fast on sums".

In an article on prenatal diagnosis in the British Medical Journal (Wald et al, 1992), the cost of preventing the birth of a child with Down's syndrome was given as $£ 38,000$ said to be "substantially less than the lifetime costs of care". When given this figure by a health economist, an obvious retort was that the child doing splendidly in the next neo-natal cot could well grow up into another Maxwell and cost the pensioners $f 600$ million, and certainly the most loved middle-class child costs his or her parents well in excess of $£ 38,000$.

There is increasing evidence that much of what was thought to be birth trauma was in fact intra-uterine damage which occurred during the first and second trimester, due to smoking, certain infections and, more rarely, lack of essential nutrients. Thus impairment of the quality of intra-uterine life threatens the well being of the foetus.

\section{Infancy}

Small or sick babies are cared for in the Special Care Baby Unit where heroic measures, involving painful invasive techniques, often without attempts at anaesthesia or even analgesics, are used. These babies, often small for dates with growth retardation already evident, suffer pain and separation from their mothers, which despite the efforts of enlightened staff often does lead to distortion of attachment as well as a much reduced chance of successful breast feeding. The fear engendered by the high tech surroundings in young, unsupported parents, overrepresented in this population, can lead to even more serious problems such as physical abuse.

\section{The baby who is different}

The legends of the changeling child have for centuries described the barrier to bonding that such a child encounters immediately after birth. The strange little face and funny shaped ears is the origin of the 
belief that the child with a "syndrome" due to a chromosomal anomaly was left maliciously by the faeries after they had stolen the "real" child. Modern legend, as depicted by 'Mr Spock' in Star Wars, can lead a couple to say that the child looks like something from outer space.

Whereas it is generally accepted that babies do not come on a sale or return basis, the unusual appearance can lead to the assumption that there is a choice in this particular case. The rate of rejection of children with Down's syndrome, by far the most common disorder to be recognised at birth to have a likelihood of at least moderate learning disability, remains at about 1 in 10, even where the services are at their best developed. However, the rare occurrence of twins both being affected is associated with an almost $100 \%$ chance of rejection.

Down's syndrome children are likely to be hypotonic, as with other children later to show spasticity, making them difficult to handle. Very irritable babies are far from rewarding to cuddle and others seem from an early age to be indifferent to affection. Thus the child who is different gets much less attention and encouragement from adults. Even those whose care demands much parental time in feeding get little of the reciprocal coo-cooing interaction that is the precursor of speech. There is thus a problem in getting stimulation as well as a brain impairment, the two leading to learning disability.

\section{Early intervention}

The concern about the primary sensory deprivation arising from birth in a child with an impairment led to the proliferation of programmes for early intervention, which initially concentrated on stimulation in the belief that the more the child was stimulated, the more he or she would learn and the less the resulting disability. Many of the programmes were based on the Head Start programme in the United States and the specialised packages developed from those initially designed for children who were thought to be of normal potential but deprived of rewarding experiences in early life. The best known and most widely used package in this country is the Portage system, developed in Wisconsin. However, over the years, there is little evidence that the final cognitive level of the child was altered but the effects were mainly on increasing parental skills, improving morale and making parents much more capable of "working the system" and obtaining better services for their children. However, some negative effects have been found in that children have undoubtedly been put under severe pressure by some programmes, with detriment to their health and the well-being of the family.

Notions of children being "at risk" made surveillance highly popular among paediatricians in the '60s. However, it began to be recognised that attendance at many different out-patient departments held few benefits for the child and often instead incurred hardship for the child and family. Following the Court report, Child Development Centres were established. Still, however, a difference of viewpoint remains. Paediatricians feel that families require "support" through regular out-patient appointments, whereas research conducted by psychiatrists indicates that this "support" could well be a considerable burden.

\section{Schooldays}

Special schools are "out" according to strict adherents of the "normalisation" concept. Yet these friendly establishments with highly skilled and enthusiastic staff are often the highlight of the itinerant developmental specialists' week as laid out in the job plan. It is so often impossible to come away without a smile and without having learnt something new. How many "ordinary" schools or even University departments reach that standard? The quality of life for the pupils is enhanced by the high staff ratio of specialised staff, but the parents are far from forgotten and most schools have an active PTA, daily reports in the 'Home and School' books and an easy access to any parent with a problem.

Integration into mainstream school is of little value if all that means is that the children with special needs are incarcerated in one class and have no shared activities with others. A girl with Down's syndrome who was one of the brightest followed from birth happily fitted into the primary school in her village but found herself very isolated in the secondary school despite her reading and arithmetic being only a year behind her chronological age. She had no friends among her peers at school but at home was preoccupied with 47 imaginary playmates.

Behaviour disorders are a serious threat to the life of a child in the community. If untreated, they can rapidly become chronic and resistant to treatment. It is behaviour rather than the extent of the learning or other disability that threatens the child's place in the school and even in his or her home, since if excluded from school then boarding school at a distance appears to be the only option available.

\section{Transition from school to adult life}

School leaving age for most children with a disability is 19 years, thanks to the energetic advocacy from parents, a group of whom even going as far as the High Court. But after the end of school, what happens next? Many of the special schools have a two year programme in the leavers' class, during which meetings are held to decide upon the next stage and then the young person may be gently introduced to 
the next stage, usually in small steps, often with some days in the new place and others still spent in the familiar environment of the school. However, the choice is limited. Although many had gone through the leavers' programme with high hopes of increased independence towards which many were confidently, albeit slowly, moving, the dream of a job sheltered from competition and danger is never fulfilled. Some adult training centres even have as their motto: "A home of my own and a job of my own". Even in happier days of full employment, that still left many out.

At the same time as they have to face the reality of an adult life that bears little resemblance to what "normalisation" was all about, comes the departure of the siblings to university, jobs away from home or to marriage. The childhood cronies are no longer there or else preoccupied with totally different problems. These factors provide a rational basis for the not uncommon depression occurring in young adults with learning disability which can lead to a loss of skills, sometimes permanently.

\section{The recognition of psychiatric disorder}

Depression is often not recognised as such in people with learning disability. Indeed the emphasis in the Mental Health Act about the distinction between mental illness and mental handicap has meant that the possibility of a co-existing mental illness, or as the Americans now call it a "dual diagnosis", has been denied. As in the psychiatry of the elderly, there may be initial difficulties in distinguishing between a depressive disorder and early dementia. Learning disability offers no immunity to the other major psychiatric disorders, and the diagnostic problems in all are considerable. Although most general surgeons come across people with significant learning disability at least as often as they occur in the general population, general psychiatrists rarely do and are therefore unfamiliar with the manifestations of, for example, schizophrenia in someone with longstanding problems of communication. The losers in this situation are people with learning disability and those keen to understand more of such a major scourge as schizophrenia.

\section{Learning disability and the law}

The needs of people with mild learning disability but significantly hampered by poor communication skills have been overlooked by the prison medical services. As yet unpublished work indicates that the quoted figure $5 \%$ of prisoners having learning disability was a gross under-estimate.

It is only in the criminal courts that those with limited ability to understand and to put forward their views are penalised as they are greatly disadvantaged in civil cases, particularly child care proceedings.

\section{Adults with physical disorder}

People with major physical and learning disability are living longer but the problems in feeding, drooling and swallowing are often ill-understood in adult services. Recent advances in the treatment of epilepsy certainly offer hope, just as long as such people are kept in touch with generic services used to prescribing the new anti-convulsants. Since many have been on neuroleptics for many years and few have the opportunity of exercise, constipation is a major source of discomfort.

When severe life-threatening illnesses occur, a junior doctor is faced with the dilemma as to whether someone who is so dependent on others should be put onto a life support system. The criteria for action, or lack of action, must be discussed well ahead and not in a crisis with juniors closely supported by consultants, including those with experience in severe disability. Quality of life considerations must include the welfare of the family and the fact that many severely disabled people are very dearly loved.

\section{Ageing family carers}

What will happen when we are gone is the persistent worry of older parents, many of whom feel that they have no right merely to pass the burden onto the next generation. It is never the right time to make decisions to part with a member of the family and hence the ideal arrangement is for gradual independence and for steadily increasing times spent away from home. Underfunded services make this ideal more and more difficult to achieve. Community care certainly depends on the unpaid carers, hence the finding in a North American study that older parents who had cared for a severely disabled child for many years were towards the end of their lives more robust and able to look back with satisfaction than comparable groups.

It is equally surprising that the old people who had been in the large "subnormality" hospitals for so long are also found to be remarkably free of both psychiatric and physical ill-health. Both of these, the long serving carers and those long ago denied an ordinary life, are the last survivors and their wellbeing now in no way justifies the tough, often deprived lives imposed upon them by society.

\section{Further reading}

GATH, A. (1990) Down's syndrome children and their families. American Journal of Medical Genetics, Supplement, 7,314-316. 
Seltzer, M. M. \& Krauss, M. W. (1989) Aging parents with adult mentally retarded children: family risk factors and sources of support. American Journal of Mental Retardation, 94, 303-312.
Wald, N. J., Kennard, A., Densem, J. W., Cuckle, H.S. et al (1992) Antenatal maternal serum screening for Down's syndrome: results of a demonstration project. British Medical Journal, 305, 391-394.

\title{
Clinical problem-solving
}

\author{
D. D. R. Williams, Consultant Psychiatrist, Cefn Coed Hospital, Swansea SA2 0GH
}

During the last 25 years there has been an unprecedented amount of change in all areas related to health care: successive re-organisation of the National Health Service, devolution of psychiatric services, structured post-graduate education, new investigations and treatment techniques, to mention a few. In a rapidly changing culture, it is timely to focus on those components of our professional work which are of enduring importance-establishing rapport with patients and families, history taking and skilful examination of the mental state - but the most important is the ability to make an accurate diagnosis which is the key to successful patient management.

There are other reasons for giving accurate diagnosis the highest profile. During the last two decades there has been an escalation of multidisciplinary working and more recently community mental health teams are being established. This is desirable practice but there are potential disadvantages. In these developments, together with some of the initiatives linked with community care, there are real anxieties that the importance of precise, clinical diagnosis is being eroded. With the active encouragement of government, more patients will be referred directly to community psychiatric nurses. In many instances this will occur without accurate diagnosis and therefore the opportunity for treatment will be missed. If no steps are taken to prevent this happening on a substantial scale, a situation of "custodial care" in the community could come about.

The importance of this subject was recently highlighted when the New England Journal of Medicine introduced a new feature: 'Clinical Problem-Solving'
(Kassiner, 1992). This innovation is devoted to looking closely at the process of how a physician in busy practice faces up to complex diagnostic, therapeutic and ethical issues. It recognised that this is at the heart of the art of medicine and that medical journals failed to teach unstructured problem-solving and had failed to reflect the challenges and rewards of the practice of medicine. It was hoped that the series would be interesting and reader-friendly in contrast to most of the original articles which contained a significant amount of technical material and to the average general reader was very heavy going. At the same time the series would provide valuable insights into how a skilled clinician arrived at crucial decisions in his work.

The change in the content of psychiatric meetings and conferences mirrors what has occurred in medical journals. Case presentation at hospital level is still universal practice but is a very infrequent event at larger psychiatric meetings. Individual case presentation is not encouraged and is frequently deemed unscientific. This is to be regretted as much can be learnt from individual cases and from the way expert clinicians handle complex information and arrive at decisions. Clinical problem-solving should be seen as a vital activity within the psychiatric profession. Its rehabilitation as a challenging essential activity is timely.

\section{Reference}

Kassiner, J. P. (1992) Clinical Problem-Solving - A new feature in the Journal. New England Journal of Medicine, $326,60-61$. 